\title{
Seizures following chloroquine treatment of type II lepra reaction: a case report
}

\author{
B. E. EBENSO \\ Qua Iboe Church Leprosy Hospital, Ekpene Obom, Box 46 Etinan, \\ Akwa Ibom State, Nigeria, West Africa
}

Accepted for publication 7 December 1997

\begin{abstract}
Summary A case of tonic-clonic seizures following chloroquine treatment for leprosy reactions in a Nigerian male is reported. Seizures were controlled with phenytoin sodium capsules. A causal relationship between the seizures and chloroquine is suggested. There have been no previous reports of this adverse reaction in leprosy patients receiving chloroquine for treatment of reactions. The author recommends that chloroquine be used with caution especially in patients with seizures.
\end{abstract}

\section{Case report}

In December 1990, a 42-year-old Nigerian male presented with a 20-year history of untreated leprosy in the outpatients' department of the leprosy referral centre for Akwa Ibom State, south-east Nigeria. Clinical signs included ill-defined hypopigmented macules with loss of sensation to tactile and thermal stimuli, multiple nodules on the chest, bilateral infiltration of the ear lobes, supercilliary madarosis and collapse of the bridge of the nose. He suffered bilateral loss of sensation of the soles of the feet and loss of sensation with absorption of the index finger and thumb of his right hand. A clinical diagnosis of borderline lepromatous leprosy was made. Skin smears showed a bacillary index (BI) of 4+. He was started on WHO multibacillary regimen (MD MDT) with dapsone, rifampicin and clofazamine. $\mathrm{He}$ made good progress but defaulted from multidrug therapy (MDT) 12 months after starting treatment.

In March 1994, he reported to the hospital with a 6-week history of fever, joint pains and eye pain. Clinical findings revealed pyrexia of $38^{\circ} \mathrm{C}$, tender deep-seated subcutaneous nodules of various sizes on the face and chest, and chronic iritis with fixed nonreacting pupils. No nerves were enlarged or tender. A voluntary muscle test and sensory test (VMT.ST) showed full strength in all muscle groups and a complete loss of sensation in his right hand and the soles of both feet. A diagnosis of erythema nodosum leprosum (ENL) reaction was made. $\mathrm{BI}$ showed $2+$. He was hospitalized and managed with: $\mathrm{i}$, chloroquine base $150 \mathrm{mg}$ three times daily for the first week; chloroquine base $150 \mathrm{mg}$ twice for the second week; chloroquine base $150 \mathrm{mg}$ daily for the third week; ii, prednisolone beginning 
with $60 \mathrm{mg}$ daily and tapering down to $5 \mathrm{mg}$ over a period of 2 weeks; iii, atropine $1 \%$ eye drops and Terracortril ${ }^{\circledR}$ eye suspension (a combination of polymyxin B, oxytetracycline hydrochloride and hydrocortisone acetate) for the iritis; and iv, MDT treatment of MB leprosy. he improved on the above treatment, and his fever and the joint pains subsided.

On the morning of the ninth day of treatment for ENL, he suffered generalized tonicclonic seizures lasting about $3 \mathrm{~min}$. There was no evidence of postictal paresis. History revealed no aetiological risk factors for epilepsy, no previous history of seizures, and no family history of epilepsy. He suffered a second episode of seizures $8 \mathrm{~h}$ later, which lasted about $7 \mathrm{~min}$. He lapsed into a postictal sleep for about $5 \mathrm{~min}$. Postseizure physical and neurological examination were normal. Cardiovascular assessment including pulse and heart sounds were normal. Laboratory investigations of CSF, blood for malaria parasites, urinalysis and blood sugar were normal. X-ray of the skull showed no abnormalities. Electroencephalogram (EEG), electrocardiogram (ECG) and CAT scan facilities are not available at Ekpene Obom.

Following the second episode of seizures, he was placed on anticonvulsive therapy (phenytoin sodium capsules, $100 \mathrm{mg}$ three times daily) with good effect for 6 days. We temporarily suspended phenytoin on the seventh day, while continuing antileprosy and antireaction drugs, and monitored the patient closely for signs of seizures. He suffered a third episode of seizures 5 days after phenytoin treatment was suspended.

After the third episode of seizures he was placed back on phenytoin capsules $(100 \mathrm{mg}$ three times daily) for 6 weeks. He did not suffer further seizures over that period. He was slowly weaned off phenytoin when the ENL reaction resolved. VMT.ST showed marked improvement, with full power in all muscle groups and restoration of sensation in his hands and soles of the feet until only the toes were anaesthetic. He was discharged to a peripheral leprosy clinic where he received monthly MDT until he was released from treatment in February 1996, at successful completion of 24 monthly doses of MB MDT. He is now on surveillance, and has remained seizure free to date (May 1997).

\section{Discussion}

Chloroquine, a 4-aminoquinoline, is most popularly used in the treatment and prophylaxis of malaria fever. Other uses ${ }^{1}$ include hepatic amoebiasis and the employment of its antiinflammatory effect in rheumatoid arthritis, lupus erythematosus and leprosy reactions (type I and type II).

Adverse effects of chloroquine include gastrointestinal disturbances, headache, ECG changes, visual disturbances, depigmentation, loss of hair, and skin reaction. ${ }^{2}$

The literature contains reports of adverse CNS effects including transient dyskinesias, ${ }^{3}$ dystonias ${ }^{4}$ and transient global amnesias. ${ }^{5}$ Tonic-clonic seizures in three Nigerian students, following therapeutic doses of chloroquine for malaria fever, ${ }^{6}$ have also been reported. Interestingly, seizures associated with the treatment of leprosy or its complications have not been reported in the literature.

The patient in question, a $78 \mathrm{~kg}$ male leprosy patient, received chloroquine tablets in doses commonly used in the therapeutic regimen for the treatment of acute inflammatory reaction in clinical leprosy. Hastings ${ }^{7}$ states that starting chloroquine in a dose of $250 \mathrm{mg}$ three times a day should be sufficient to control type II reaction within a week. The dose is then lowered to $250 \mathrm{mg}$ twice daily for a week, followed by $250 \mathrm{mg}$ daily to maintain control 
of the reaction. However, our patient suffered three episodes of generalized tonic-clonic seizures without evidence of focal onsets while receiving treatment for ENL reactions. The possible aetiology of seizures in the above patient includes: intercurrent infections, hypoglycaemia, space occupying lesion of the brain, adverse drug reaction or interaction, and idiopathic epilepsy.

It is unlikely that the seizures were caused by intercurrent infections as revealed by laboratory investigations. The absence of symptoms and signs of hypoglycaemia (anxiety, shakiness, palpitations, coma, hypothermia and irritability) ${ }^{8}$ before and after seizures, and a normal fasting blood glucose concentration rule out the possibility of hypoglycaemia inducing seizures in the patient. Furthermore, one would expect subsequent seizures over the past 3 years since discontinuing phenytoin, if seizures were due to a growing space occupying lesion or idiopathic epilepsy. However, the author acknowledges an EEG and CAT scan would settle the above suspicion.

A likely explanation for seizures in the patient would be a drug-induced adverse reaction. Prednisolone, dapsone, rifampicin and clofazamine have not been associated with seizures. Of the drugs used in the management of reactions in leprosy, only chloroquine has been reported in the literature to be associated with seizures, especially in susceptible individuals. Tonic-clonic seizures have been reported following prophylactic, ${ }^{9}$ therapeutic ${ }^{10}$ and toxic ${ }^{11}$ doses of chloroquine used either alone or in combination with other antimalarial drugs or antibiotics for the management of malaria or amoebiasis.

From the above, it is logical to suspect chloroquine, acting alone or interacting with MDT or prednisolone, as inducing seizures in the patient for the following reasons:

He received chloroquine while on treatment for ENL reactions.

He suffered seizures during the period of treatment for ENL.

Seizures were controlled with phenytoin sodium capsules but recurred when the phenytoin was temporarily suspended while he was still taking chloroquine, prednisolone and MDT. We continued chloroquine treatment in spite of the seizures because we were unaware of chloroquine-induced seizures prior to our literature search.

Seizures stopped when chloroquine was withdrawn after the third week of treatment.

No further seizures were observed even when phenytoin was finally stopped and ENL resolved.

The mechanism of seizure induction by chloroquine in the above patient is unclear. Chloroquine inhibits glutamate dehydrogenase activity ${ }^{11}$ and could reduce concentrations of the inhibitory neurotransmitter gamma aminobutyric acid (GABA). ${ }^{9}$ Torrey states that seizure induction by chloroquine could be due to an idiosyncratic adverse reaction in sensitive individuals. ${ }^{11}$

Seizure induction in this patient is thought to be an idiosyncratic adverse reaction to chloroquine and not due to toxic effects, as he was receiving chloroquine in doses (of $150 \mathrm{mg}$ base given up to three times daily), ${ }^{12}$ compatible with therapeutic regimen for the management of leprosy reactions in adults. Deliberate ingestion of an overdose of chloroquine by the patient is unlikely, as his antireaction drugs were administered by a nurse.

This report highlights the potential risk of seizures in patients receiving chloroquine for the treatment of leprosy reactions. The author recommends that health workers use chloroquine with caution, especially in patients with a history of seizures. Patients who suffer chloroquine-induced seizures may require alternative antireaction drugs. 


\section{Acknowledgement}

I thank Dr Desmond Soares and Dr Irene Brightmer for their comments on an earlier version of this paper.

\section{References}

${ }^{1}$ Laurence DR, Bennett PN. Clinical pharmacology, 5th edition. Churchill Livingstone, Edinburgh; 1980, p 291.

British Medical Formulary, No. 28, Sept. 1994.

${ }^{3}$ Bhargava RK, Parakh KL, Hakim A, Govim, Bhandari NC. Extrapyramidal syndrome after anti-malarial. J Assoc Phys India, 1973; 21: 969-973.

${ }^{4}$ Umez-Eronini EM, Erorini EA. Chloroquine induced involuntary movements. Br Med J, 1977; 945-946.

${ }^{5}$ Cras P, Martin JJ. Transient global amnesia following ingestion of chloroquine. J Neurosurg Psychiatry, 1990; 50: 926.

6 Adamolekun B. Seizures associated with chloroquine therapy. Cent Afr J Med, 1992; 38: 350-352.

${ }^{7}$ Hastings RC. Leprosy, 1st edition. Churchill Livingstone, Edinburgh; 1985, p 216.

8 Wyngaarden JB, Smith LH. Cecil textbook of medicine, 17th edition. Saunders, Philadelphia; 1985, pp 13421343.

9 Fish DR, Espir MLE. Convulsions associated with prophylactic anti-malarial drugs: implications for people with epilepsy. Br Med J, 1988; 297: 526.

10 Adamolekun B. Epileptogenic potential of anti-malarial drugs. W Afr J Med, 1993; 12: 231-232.

11 Torrey EF. Chloroquine seizures. JAMA, 1968; 204: 867-870.

12 Bryceson A, Pfalzgraff RE. Leprosy, 3rd edition. Churchill Livingstone, Edinburgh; 1990, p 128. 